\title{
The Hydrogenation of Unsaturated Fatty Acids by Five Bacterial Isolates from the Sheep Rumen, Including a New Species
}

\author{
By P. KEMP, R. W. WHITE AND D. J. LANDER \\ Department of Biochemistry, ARC Institute of Animal Physiology, \\ Babraham, Cambridge CB2 $4 A T$
}

(Received 5 February 1975; revised 26 April 1975)

SUMMARY

Five strictly anaerobic bacteria able to hydrogenate unsaturated fatty acids were isolated from sheep rumen. One was characterized as Ruminococcus albus, two as Eubacterium spp. and two as Fusocillus spp., one of which is named as a new species. The Fusocillus organisms were able to hydrogenate oleic acid and linoleic acid to stearic acid, and linolenic acid to cis-octadec-I5-enoic acid. The $R$. albus and the two Eubacteria did not hydrogenate oleic acid but converted linoleic and linolenic acids to a mixture of octadecenoic acids; trans-octadec-I I-enoic acid predominated but several isomeric cis and trans octadecenoic acids were produced together with isomers of non-conjugated octadecadienoic acids.

The intermediate and final products of hydrogenation by each organism were compatible with the results from mixed rumen bacteria.

\section{INTRODUCTION}

The hydrogenation of dietary fatty acids in the rumen has been reviewed in detail by Dawson \& Kemp (1970) and by Viviani (1970). The identities of the major intermediates in the hydrogenation of $\alpha$-linolenic acid and linoleic acid were established by in vitro incubations of ${ }^{\mathrm{I}}{ }^{14} \mathrm{C}$-labelled substrates (Wilde \& Dawson, I966; Dawson \& Kemp, 1970). Noble, Steele \& Moore (1969) showed that the same major pathways operate in vivo.

Efforts to obtain active preparations from the broken cells of mixed populations of rumen organisms have been unsuccessful, but Kepler \& Tove (1967) tried to obtain active enzyme systems from disrupted cells of a strain of Butyrivibrio fibrisolvens, a rumen bacterium which had earlier been shown to hydrogenate both $\alpha$-linolenic and linoleic acid to transoctadec-II-enoic acid (Polan, McNeill \& Tove, I964; Kepler et al. I966). Only the isomerase which catalysed the first step in the process was isolated. Subsequent work (Kepler, Tucker \& Tove, 1970) demonstrated that a double bond in the 9-10 position and a free carboxyl group were necessary for hydrogenation, as was found by Garton, Lough \& Vioque (I96I) and Hawke \& Silcock (I969) who showed that the fatty acids of triglycerides were hydrogenated only after lipolysis. Recently this has been shown to be true for the fatty acids of the galactosylglycerides of grass (Dawson et al. 1974). Attempts to find the source of reducing power and the immediate hydrogen donor in mixed populations (Viviani, 1970) and in B. fibrisolvens (Rosenfeld \& Tove, I97I) met with little success.

Activity was detected by Mills et al. (1970) in a micrococcus isolated by Russell \& Smith (1968) and by Sachan \& Davis (1969) in a Borrelia sp. Both organisms, like B. fibrisolvens, produced trans-octadec-I I-enoic acid from $\alpha$-linolenic and linoleic acids.

In 1968 we began a programme of systematic screening of rumen bacteria for their ability 
to hydrogenate linolenic acid, linoleic acid and oleic acid. We have examined more than 200 isolates. Thirty showed limited activity, and of these only five had sufficient activity to warrant further work.

The isolation in pure culture, the identification of these five bacteria (one as a new species) and the separation and characterization of their hydrogenation products is described in this paper.

Some preliminary aspects of this work have been reported (Kemp \& White, 1968; White, Kemp \& Dawson, I970; White \& Kemp, I97I).

\section{METHODS}

Isolation and testing of bacteria. For initial isolations, subsequent culturing and for all hydrogenation activity testing, the medium of Bryant \& Robinson (I96I) with the addition of $0 . I \%(w / v)$ yeast extract was used, the agar concentration being increased to $I \cdot 25 \%$ $(\mathrm{w} / \mathrm{v})$ for roll bottles. This medium is referred to throughout as the basic medium. All tubes and roll bottles of basic medium were gassed with $\mathrm{O}_{2}$-free $\mathrm{CO}_{2}$ and closed with butyl rubber bungs [Charles W. Meadows (London) Ltd, Torquay, Devon]. Incubations were initially for $72 \mathrm{~h}$ at $39^{\circ} \mathrm{C}$, but since it was found that viable bacterial numbers were maximal at about $20 \mathrm{~h}$ subsequent hydrogenation incubations were not usually carried beyond $24 \mathrm{~h}$.

For colony isolation and for any situations where other reducing mechanisms might not be operative, or where aeration risks during handling were high, levels of L-cysteine were increased from the $0.25 \mathrm{mg} / \mathrm{ml}$ normally used, to as high as $2.5 \mathrm{mg} / \mathrm{ml}$.

Utilization of carbohydrates, alcohols and organic acids was tested by substituting them, at a concentration of $5 \mathrm{mg} / \mathrm{ml}$, for the glucose, starch and cellobiose normally added to the basic medium. Unequivocal growth was accepted as a positive result.

Culture fluids with $\mathrm{HCl}$ added to $\mathrm{O} \cdot \mathrm{I} \mathrm{M}$, were analysed directly for volatile fatty acids using a Tween-80 column ( $20 \%$ on gas-chrom Z; Pye-Unicam Ltd) at $130^{\circ} \mathrm{C}$. Lactic and succinic acids were estimated as their methyl esters by g.l.c. at 75 and $130^{\circ} \mathrm{C}$ respectively, using a $10 \%$ PEG A column. In addition, lactic acid was estimated enzymically by the method of Barker \& Britton (I957).

De-carboxylases, arginine dihydrolase, catalase and the reduction of gluconate and nitrate were all tested for according to the methods described by Cowan \& Steel (1966), under anaerobic conditions. Casein hydrolysis was tested in roll bottles of basic medium containing $0.5 \%(\mathrm{w} / \mathrm{v})$ light white casein. Liquefaction of gelatin was tested by adding gelatin-charcoal discs (Oxoid) to tubes of basic medium. Hydrogen sulphide formation was detected by the method of Bryant \& Small (1956), except that the ferrous salt was substituted for the ferric and it was sterilized under nitrogen.

Rumen fluid, both as inoculum material and as a constituent of the basic medium, was obtained from Clun Forest sheep, each having a permanent rumen cannula. The animals were permanently housed, and received a maintenance diet of $1000 \mathrm{~g}$ hay chaff and $100 \mathrm{~g}$ oats daily, with water $a d l i b$ and access to a mineral lick.

Bacteria were initially isolated (in tubes of liquid basic medium) by arbitrarily subculturing 30 to 40 colonies at a time from roll bottles which had contained solidified basic medium, $2.5 \mathrm{mg} \mathrm{L}$-cysteine $/ \mathrm{ml}$, and dilutions of fresh rumen fluid. Gram-stained films from all cultures were examined, and isolates were roughly sorted and screened for hydrogenation activity in the basic medium. Dilutions of cultures of active isolates were again cultured in roll bottles of basic medium. From the highest dilutions, 5 to Io colonies were subcultured. Growth in these subcultures was examined and cultures were again tested for hydrogenation 
activity. This procedure was repeated until the purity of strains associated with hydrogenation activity had been established. The final active isolates were obtained, at levels of $10^{7}$ to $10^{8} / \mathrm{ml}$, from four different animals.

Electron microscopy. Several cultures of each organism were negatively stained with $2 \%$ sodium phosphotungstate $\mathrm{pH} 7 \cdot 2$ and examined in the electron microscope. The cultures were sampled directly, or after concentrating the bacteria by centrifugation for I $\mathrm{min}$ in an Eppendorf 3200 centrifuge (Eppendorf-Geratebau, Hamburg, Germany).

Fatty acids. ${ }^{\mathrm{I}}{ }^{14} \mathrm{C}$-labelled oleic, linoleic, linolenic and palmitic acids were obtained from the Radiochemical Centre, Amersham, Buckinghamshire, and stored in benzene solution $(5 \mu \mathrm{Ci} / \mathrm{ml})$ at $-20^{\circ} \mathrm{C}$. A small impurity of trans acids, which increased slowly on storage, was found in these preparations.

Unlabelled oleic, linoleic, linolenic, cis-vaccenic, palmitic and stearic acids were from Sigma.

Trans-octadec-9-enoic acid (elaidic acid) was prepared by the selenium isomerization of oleic acid (Swern \& Scanlan, 1953) and purified by thin-layer chromatography of the methyl ester (see below). A mixture of trans-octadecenoic acids containing mainly transoctadec-I I-enoic acid was prepared by argentation-t.l.c. of the methyl esters of the products obtained by incubating organism F2/2 with linoleic acid. Cis-octadec-15-enoic acid was prepared in a similar way from the products obtained by incubating organism $\mathrm{P} 2 / 2$ with linolenic acid.

Preparation of fatty acid substrates. Substrates added to uninoculated media were dried, from benzene solution under nitrogen, as a film around the lower part of the incubation tube. Medium was then added and the tube autoclaved, sterile reducing agent added and the medium equilibrated with $\mathrm{CO}_{2}$ and inoculated. When substrate was to be added to a growing culture or suspension of bacteria it was dissolved in sufficient methanol to give a solution when sterile buffer (Coleman, 1958) was added. The methanol was removed either with $\mathrm{N}_{2}$ at $40^{\circ} \mathrm{C}$ or in a rotary evaporator, and the resulting emulsion finally sonicated for $30 \mathrm{~s}$ in a Kerry's ultrasonic cleaning bath type KB80, frequency $80 \mathrm{kHz}$ [Kerry's (Ultrasonics) Ltd, Basildon, Essex].

Extraction of lipids and preparation of fatty acid methyl esters. Incubations were stopped, and the total lipids extracted, by adding the cultures to Io volumes of chloroform-methanol$5 \mathrm{M}-\mathrm{HCl}$ (5:6: I, by vol.) containing $50 \mathrm{mg} \mathrm{2,6-di-t-butyl-4-methylphenol/1.} \mathrm{After} 20 \mathrm{~min}$, water ( 2 vol.) was added and the mixture shaken. The lower, $\mathrm{CHCl}_{3}$-rich phase was taken to dryness on a rotary evaporator and the lipids hydrolysed by refluxing for $\mathrm{I} h$ with $6 \%$ $(\mathrm{w} / \mathrm{v}) \mathrm{KOH}$ in ethanol-water (I9: I, v/v). After cooling, an equal volume of water was added and the mixture extracted three times with half a volume of light petroleum (b.p. 40 to $60^{\circ} \mathrm{C}$ ) to remove the unsaponified material. The mixture was then acidified with $\mathrm{HCl}$ and extracted three times with light petroleum. The last three extracts, containing free fatty acids, were pooled and taken to dryness on a rotary evaporator. The fatty acids were dissolved in diethyl ether-methanol $(9: 1, v / v)$ and methylated with freshly-distilled diazomethane (Schlenk \& Gellerman, 1960).

Gas- and radio-gas-chromatography. Fatty acid methyl esters were analysed using a Pye I04 gas-chromatograph fitted with flame ionization detectors and $5 \mathrm{ft} \times \frac{3}{16}$ inch glass columns packed with either polyethyleneglycol-adipate (PEGA; $10 \%$ on Diatomite CAW) or SE 30 (3\% on Diatomite CQ), all from Pye-Unicam Ltd, Cambridge.

The columns were maintained at either 184 or $197^{\circ} \mathrm{C}$ for PEGA and $197^{\circ} \mathrm{C}$ for $\mathrm{SE}_{30}$. Argon- $\mathrm{CO}_{2}(19: \mathrm{I}, \mathrm{v} / \mathrm{v})$ was used as carrier gas at $60 \mathrm{ml} / \mathrm{min}$. A stream splitter allowed 90 to $95 \%$ of the effluent gases to bypass the detector and pass through a heated combustion tube 
packed with copper oxide followed by iron filings. The resulting ${ }^{14} \mathrm{CO}_{2}$ was piped to a Panax radio-gas counter (Panax Equipment Ltd, Redhill, Surrey).

Position and geometry of double bonds. The fatty acid methyl esters were separated preparatively, according to the degree of unsaturation and the geometry of the double bonds, by t.l.c. on $250 \mu \mathrm{m}$ layers of silica gel $\mathrm{H}$ (Kieselgel $\mathrm{H}$. Nach Stahl; Merck) containing $\mathrm{I} 4 \%$ $(\mathrm{w} / \mathrm{w}) \mathrm{AgNO}_{3}$; benzene-hexane $(\mathrm{I}: \mathrm{I}, \mathrm{v} / \mathrm{v})$ or benzene-diethyl ether $(99: \mathrm{I}, \mathrm{v} / \mathrm{v})$ which were used to develop the plates. Radioactive components were located either with a windowless scanning flow-counter or by autoradiography (FP4 fine grain glass plates; Ilford, Essex). Nonradioactive components on the plates were visualized by viewing under u.v. light after spraying with $0.2 \%(\mathrm{w} / \mathrm{v})$ 2,7-dichlorofluorescein in ethanol. Appropriate standards chosen from methyl stearate, oleate, elaidate, linoleate and $\alpha$-linolenate were spotted on to one edge of the plate to assist in the identifications. Areas of the plate where fatty acid methyl esters were detected were carefully scraped off and the esters eluted from the silica gel with diethyl ether, or, if polar compounds were suspected, with $\mathrm{CHCl}_{3}-\mathrm{MeOH}(\mathrm{I}: \mathrm{I}, \mathrm{v} / \mathrm{v})$. The identities of the fatty acid methyl esters in each eluate were checked by g.l.c., and the double bond positions in the cis and trans monoenoic acid methyl ester bands were determined by oxidative cleavage at the double bond by the periodate permanganate method of von Rudloff (1956). The dicarboxylic acid monomethyl esters produced were methylated and analysed by g.l.c. on PEGA. A mixture of the dimethyl esters of dicarboxylic acids of known chain length was used as external standard (dicarboxylic acids $C_{6}$ to $C_{15}$; Analabs Inc., North Haven, Connecticut, U.S.A.). Since the parent $C_{18}$ acid was usually ${ }^{1}{ }^{14} C$-labelled, and the dicarboxylic acids were also ${ }^{\mathrm{I}}{ }^{14} \mathrm{C}$-labelled, no routine analysis was done to identify the monocarboxylic acids derived from the methyl end of the chain. Methyl esters of acids with two or three double bonds were subjected to partial reduction with hydrazine hydrate in ethanol- $\mathrm{H}_{2} \mathrm{O}$ (19: I, v/v) (Privett \& Nickell, 1966; Kemp \& Dawson, 1968; Roehm \& Privett, I969). The products were separated on $\mathrm{AgNO}_{3}$-impregnated plates using benzene-hexane $(\mathrm{I}: \mathrm{I}, \mathrm{v} / \mathrm{v})$. The bands containing the cis and trans monoenoic acid methyl esters were eluted and their bond positions determined as described above. Dienoic acids which were produced as intermediates during the reduction of trienoic acids were sometimes isolated and again subjected to partial reduction to yield monoenoic acids. The position and geometry of the double bonds in these dienoic acids assisted in the determination of the structure of the parent trienoic acid.

\section{RESULTS}

\section{Active bacterial isolates}

The Gram-positive coccus F2/6 and the Gram-positive bacilli F2/2 and w46I could all hydrogenate linolenic and linoleic acid to a mixture of trans octadecenoic acids but not to stearic acid. The Gram-negative bacilli P2/2 and T344 could hydrogenate oleic and linoleic acid to stearic acid, and linolenic acid to, mainly, cis-octadec-I5-enoic acid.

Isolates F2/2 and F2/6 were obtained from the same sheep, and isolates P2/2, T344 and W46I were each from a different sheep. Originally, W46I and P2/2 were two-component cultures, which were taken through at least 20 alternate roll-bottle cultures and subcultures of individual colonies taken from these, until in each case an active hydrogenating component and an inactive component were separated. The inactive organisms were discarded since no enhancement of activity was found in mixed culture. The preliminary description of W46I (White \& Kemp, 1971) was based on this two-component culture before it had been separated, and was incorrect. The report by Orpin \& Munn (1974) from this laboratory, 
Table I. Growth and production of organic acids by the bacterial isolates

The basic medium contained glucose, starch and cellobiose. For fermentation tests these were replaced by the single compounds noted in the first column.

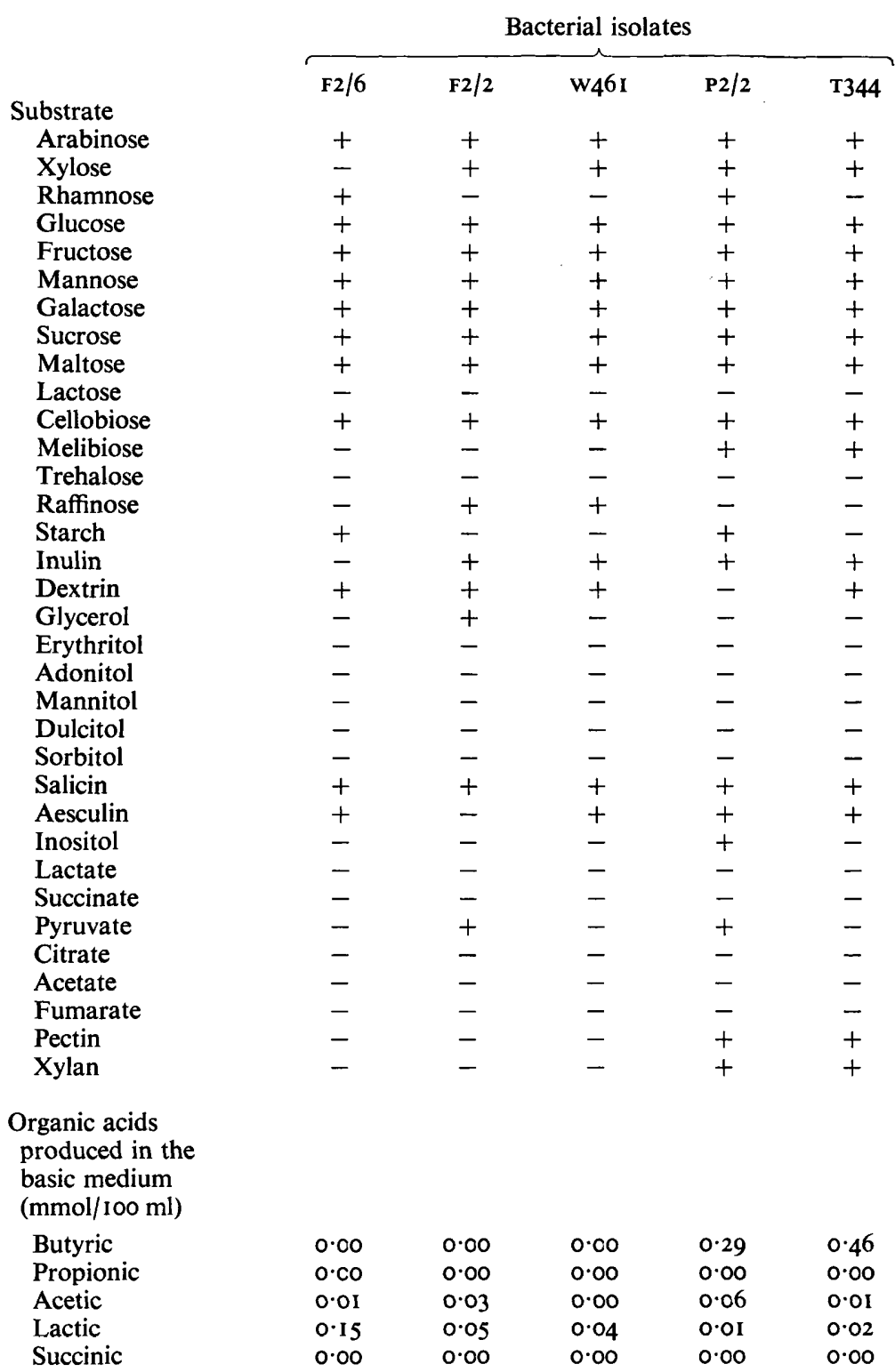

+ , Growth; -, no growth. 

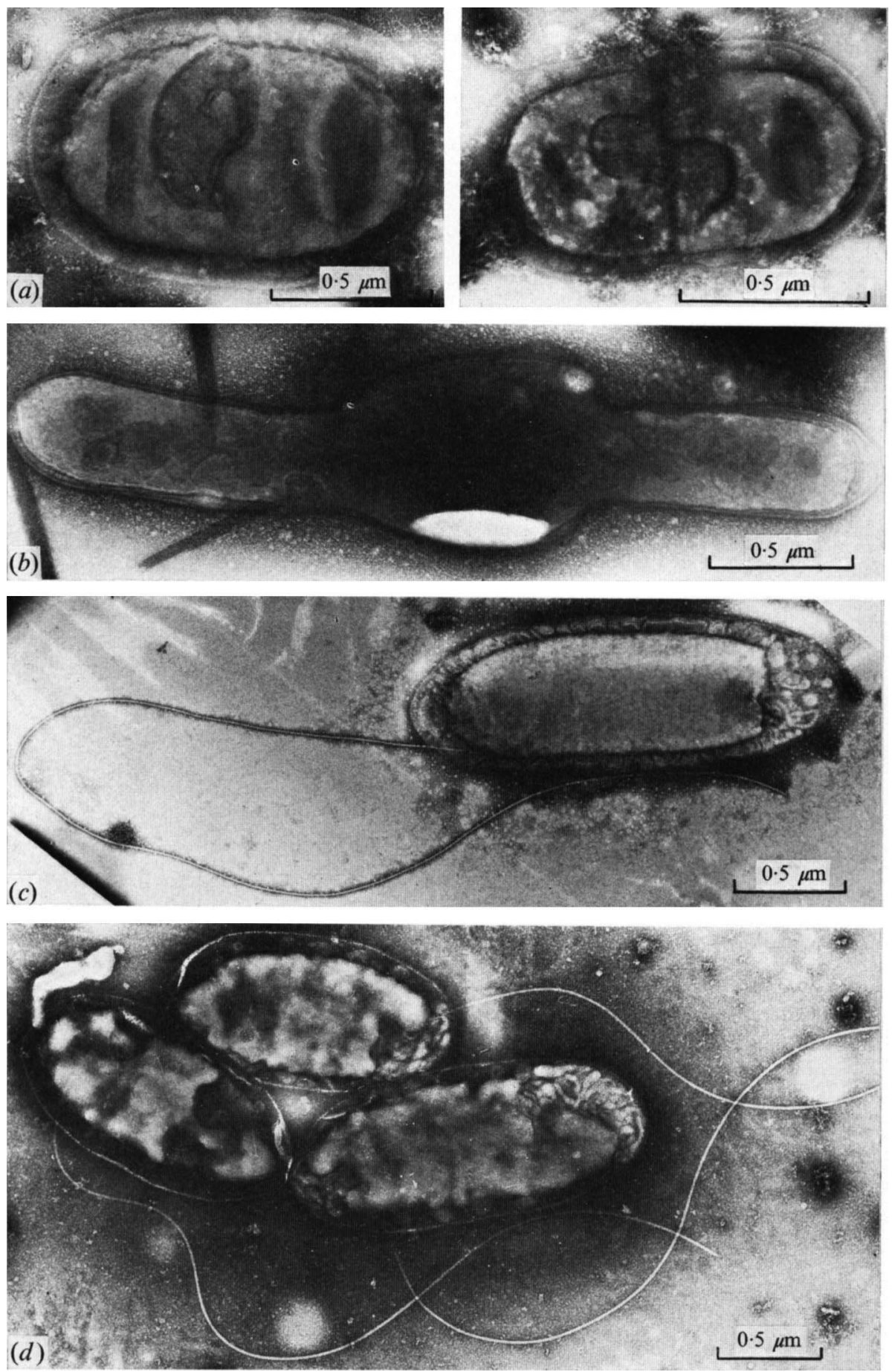

Fig. I. Electron micrographs of (a) F2/6, (b) F2/2, (c) P2/2, and (d) $\mathrm{r} 344$. 
describing bacteriophages $\mathrm{W}_{46} \mathrm{I} \psi \mathrm{I}$, was also based on the mixed culture and refers to the inactive component.

\section{Characterization}

The results of growth tests and of organic acid production in the basic medium are set out in Table $\mathrm{I}$.

None of the five organisms produced $\mathrm{H}_{2} \mathrm{~S}$. All were catalase-negative, and failed to reduce gluconate or nitrate, to liquefy gelatin or to digest casein. No decarboxylases to lysine or ornithine were demonstrated. However, the test procedure used appeared not to permit vigorous growth of the organisms. All five organisms were strict anaerobes.

The Gram-positive coccus F2 $/ 6$, measuring I $\times 0.5 \mu \mathrm{m}$ (Fig. I a), frequently displayed a marked streptococcus-like morphology, particularly in a serum medium. It was heat resistant $\left(60^{\circ} \mathrm{C}\right.$ for $\left.30 \mathrm{~min}\right)$ and a narrow capsule could be observed in indian ink preparations. A grouping precipitation test (Lancefield, 1933) against sera of groups A, B, D, G, $\mathrm{F}, \mathrm{H}, \mathrm{K}, \mathrm{N}$ and $\mathrm{P}$ was negative. This amylolytic organism showed some similarities to the rumen coccus which Provost \& Doetsch (1960) designated as a Gram-negative Peptostreptococcus sp. (although their isolate was stated to be heavily granulated in young cultures). Our strain was morphologically much more variable, and had no proteolytic activity. Gutierrez et al. (1959) have described rumen organisms similar to Streptococcus bovis, but heavily capsulated, producing sufficient dextran to form obvious slime in the presence of specific carbohydrates. When grown in the presence of these carbohydrates F2/6 failed to produce obvious slime or increased capsules. Strain F2/6 was designated Ruminococcus albus, on the basis of morphology in the basic medium, anaerobiosis, and general fermentative properties.

Strains F2/2 and w46I are both Gram-positive bacilli, $2.5 \times 0.5 \mu \mathrm{m}$, non-motile, with no demonstrable flagellum. Strain $\mathbf{F} 2 / 2$ in particular displayed an occasional central swelling (Fig. I $b$ ) which was apparently not a spore. Cultures did not survive heating to $80{ }^{\circ} \mathrm{C}$ for Io min, nor to $60^{\circ} \mathrm{C}$ for $30 \mathrm{~min}$. No particular age or condition of culture obviously affected the numbers of bacilli showing the central swelling. An exactly similar morphology was described by Walker (I96I) for a xylan-utilizing rumen bacillus. Our isolates did not utilize hay xylan, prepared by D. Jordan in this laboratory by the method of Chanda et al. (1950). Both strains lost Gram-stain easily. Both were assigned to the genus Eubacterium with no species diagnosis.

Isolates P2/2 (Fig. I c) and T344 (Fig. I $d$ ) were Gram-negative flagellated bacilli, 2 to $3 \times 0.75 \mu \mathrm{m}$. Strain P2/2 (Fig. I c) was the first strain capable of the biohydrogenation of linoleic acid and oleic acid to stearic acid to be isolated. Under all conditions of growth, both P2/2 and T344 displayed a typical spindle-shaped morphology under the light microscope. Vigorous motility was readily observed in young cultures in sealed, hanging-drop preparations or in the Helba counting-chamber preparations made for total counts of cultures during the biohydrogenation time-course experiments described later. The method of using soft agar basic medium in U-tubes inoculated at one end, and observing migration as a test of motility, did not work for these or any other rumen anaerobes in our hands. A single, long, sub-polar flagellum was seen in electron microscope preparations (Fig. I $c, d$ ). Butyric acid but no acetic or propionic acid was produced from glucose (Table I). On the basis of the larger size and different morphology, we have separated our isolates quite clearly from the Butyrivibrio spp. and assigned them to Fusobacteria. Holdeman \& Moore (1973) do not include organisms having a single sub-polar flagellum in their Fusobacterium genus. All their motile species of this genus produce succinic acid from glucose and they do 


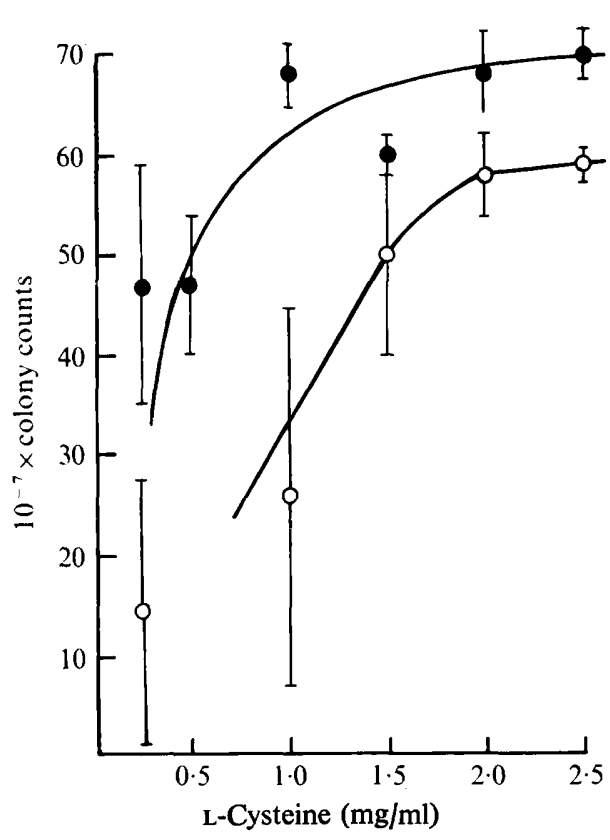

Fig. 2

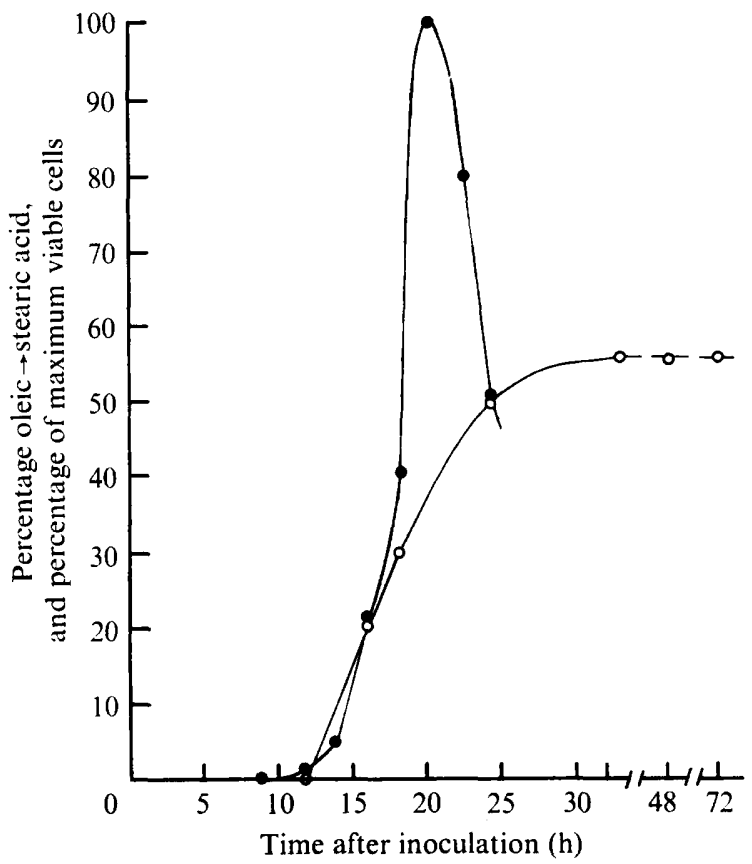

Fig. 3

Fig. 2. Colony counts in $(O)$ roll bottles and $(O)$ counting flasks (White, 1970), using the basic medium inoculated with diluted rumen fluid, and varying the levels of L-cysteine. Vertical bars indicate standard deviations.

Fig. 3. Time course of growth and hydrogenation of oleic acid by P2/2. Tubes of the basic medium containing oleic acid were inoculated with $\mathrm{P} 2 / 2$ and incubated at $39{ }^{\circ} \mathrm{C}$. At each interval two tubes were pooled for hydrogenation tests $(O)$ (details in text) and dilutions from a single tube were inoculated into roll bottles to assess numbers of viable bacteria $(\theta)$. The tube contained $10^{3}$ bacteria $/ \mathrm{ml}$ when inoculated, and $4 \times 10^{8}$ viable bacteria $/ \mathrm{ml}(\equiv 100 \%)$ at $20 \mathrm{~h}$.

not mention Fusocillus. Bryant (1959) refers briefly to Fusobacteria as possible rumen organisms; Hungate (I966) does not mention this group. Lev (1958) isolated from the rumen of a cow a Fusiformis nigrescens which had a particular requirement for vitamin $\mathrm{K}$. Our isolates showed no stimulation response to menadione, haemin or blood. The two isolates are assigned to the Fusocillus sp. of Sebald (1962), and may be similar to the Fusocillus sp. obtained by Barnes \& Burton (1970) from the caecum of hibernating ground squirrels. Strain T344 is a Fusocillus sp. with no species diagnosis. Strain P2/2 is named as a new species: Fusocillus babrahamensis nov. spec., Gram-negative, non-sporing bacillus; motile, single sub-polar flagellum, strictly anaerobic, spindle-shaped, fermentatively active, produces butyric acid but not succinic acid from glucose, hydrogenates oleic and linoleic acids to stearic acid, and $\alpha$-linolenic acid to cis-octadec-I 5-enoic acid; isolated from the rumen of a sheep; NCIB number 10838 .

All five isolates have been freeze-dried and deposited with the National Collection of Industrial Bacteria (White, MacKenzie \& Bousfield, I974). 


\section{Reducing agents}

Figure 2 shows the result, as colony counts in roll bottles and in counting flasks (White, 1970), of using increasing levels of L-cysteine in basic medium without yeast extract which had been inoculated with dilutions of fresh rumen contents. Levels of L-cysteine up to 2.5 $\mathrm{mg} / \mathrm{ml}$ have been used frequently throughout; no observable effect on bacterial growth or biochemical activity was ever detected.

Dithiothreitol (Cleland, I964), when used together with L-cysteine, was found by Moore (1968) to have an additive effect in stimulating surface colony growth of a fastidious Clostridium sp. It is possible that this was an improved reduction effect similar to that found here when using high levels of L-cysteine.

Using the basic liquid medium and cultures of the five isolates we compared the results of using L-cysteine $(0.25 \mathrm{mg} / \mathrm{ml})$ with those obtained with dithiothreitol $(\mathrm{I} \cdot 5 \mathrm{mg} / \mathrm{ml})$, either alone or in combination with L-cysteine $(0.25 \mathrm{mg} / \mathrm{ml})$, ascorbic acid ( $10 \mathrm{mg} / \mathrm{ml})$, reduced glutathione $(\mathrm{I} \mathrm{mg} / \mathrm{ml})$ or sodium thioglycolate $(\mathrm{I} \mathrm{mg} / \mathrm{ml})$. Hydrogenation levels after $24 \mathrm{~h}$ were almost identical with those for L-cysteine alone, and although viable counts were not done, growth was not visibly affected by any of the treatments.

\section{Hydrogenation studies}

Cultures were grown for 20 to $24 \mathrm{~h}$ after heavy inoculation ( $0.05 \mathrm{ml}$ into $5 \mathrm{ml}$ ) from $24 \mathrm{~h}$ cultures. Substrate fatty acids were added at 2 to $20 \mu \mathrm{g} / \mathrm{ml}$. With each organism, increasing the substrate levels of linoleic and linolenic, but not oleic, acids resulted in an increase of intermediates relative to the final product, and the higher substrate levels were sometimes used to obtain sufficient of these intermediates for structural studies.

Figure 3 shows that the hydrogenation of oleic to stearic acid by P2/2 closely follows the growth of the organism. With linoleic acid or linolenic acid as the substrate, the first intermediate (a conjugated dienoic acid or a conjugated trienoic acid) was observed 12 to $15 \mathrm{~h}$ after inoculation. The four other organisms were very similar to $\mathbf{P} 2 / 2$ in their time courses of hydrogenation and growth.

Table 2 shows products recovered and identified after incubating the five organisms with oleic acid, linoleic acid and linolenic acid. Strains P2/2 and T344 were the only organisms of the 30 hydrogenating strains which showed any ability to hydrogenate oleic acid to stearic acid. There was no evidence to show unequivocally that oleic was hydrogenated via an intermediate to stearic acid. No cis acids other than the substrate were ever recovered from the incubations, and oleic acid was apparently hydrogenated more readily to stearic acid than was cis-octadec-II-enoic acid, trans-octadec-9-enoic acid or trans-octadec-II-enoic acid.

A polar acid, identified by g.l.c., t.l.c. and mass spectrometry as an hydroxystearic acid, was always recovered from incubations of $\mathbf{P 2} / 2$ with oleic acid but not with other cis or trans octadecenoic acids. This polar acid was not metabolized further in our incubation system and it does not appear that it could be an intermediate. About $5 \%$ of the oleic acid substrate was recovered as trans-octadec-II-enoic acid in incubations with T344 but, as stated above, this acid was not more readily converted to stearic acid than was oleic acid.

The conjugation of linoleic acid to cis,trans-octadec-9, I I-enoic acid and linolenic acid to cis,trans,cis-octadec-9, I I,I5-enoic acid is the first step in the hydrogenation of these two acids by all five organisms. Even at very short times of incubation, rarely was more than $10 \%$ of the substrate recovered as the conjugated product. With w46I the yields were so 


\section{Table 2. The products and intermediates of hydrogenation}

Fatty acids are abbreviated as follows: The number of carbons in the paraffin chain is indicated before the colon, and the number of double bonds after the colon (e.g. I 8:2, for octadecadienoic acid). This is followed by the position and configuration of the double bonds, numbering from the carboxyl end of the chain (e.g. I 8:3,9c, I It, I5c for cis,trans, cis-octadec-9, I 1, I5-enoic acid). The major end products are indicated in heavy type.

\begin{tabular}{|c|c|c|c|}
\hline Organism & Substrate & Major products & Isomers and other products \\
\hline \multirow[t]{3}{*}{$\mathrm{P} 2 / 2$} & $\begin{array}{r}18: 1,9 \mathrm{c} \\
\text { (oleic) }\end{array}$ & 18: o (80 \%) & I8-OH $(20 \%)$ \\
\hline & $\begin{array}{l}\text { I 8:2,9c, I } 2 \mathrm{c} \\
\text { (linoleic) }\end{array}$ & $\begin{array}{l}\text { (i) Conjugated } 18: 2,9 c, \text { I It } \\
\text { (ii) } 18: 1, \text { I It }(70 \%) \\
\text { (iii) } 18: 0\end{array}$ & $9 t(15 \%)$, iot $(10 \%)$ \\
\hline & $\begin{array}{l}\text { I } 8: 3,9 \mathrm{c}, \text { I } 2 \mathrm{c}, \mathrm{I} 5 \mathrm{c} \\
\text { (linolenic) }\end{array}$ & $\begin{array}{l}\text { (i) Conjugated } 18: 3,9 c, \text { I It, } 15 \mathrm{c} \\
\text { (ii) } 18: 2, \text { I } \mathrm{It}, \mathrm{I} 5 \mathrm{c} \\
\text { (iii) } \mathrm{x8}: \mathrm{r}, 15 \mathrm{c}(85 \%)\end{array}$ & I5t $(10 \%)$, i 4 t $(4 \%)$, , 3 t ( $\%)$ \\
\hline \multirow[t]{3}{*}{ T344 } & Oleic & 18:0 & I8: I, IIt (5\%) \\
\hline & Linoleic & $\begin{array}{l}\text { (i) } 18: 2,9 \mathrm{c}, \text { I It } \\
\text { (ii) } 18: 1,1 \mathrm{It}(65 \%) \\
\text { (iii) } 18: 0\end{array}$ & I3t, I 2t, I4t, Iot (trace 9c) \\
\hline & Linolenic & $\begin{array}{l}\text { (i) } 18: 3,9 \mathrm{c}, \text { I I t, I } 5 \mathrm{c} \\
\text { (ii) } 18: 2, \text { I It, I } \mathrm{c} \\
\text { (iii) } 18: 1,15 \mathrm{c}(85 \%)\end{array}$ & $\begin{array}{l}\text { Trace } 9 c, 15 c \text { and } 1 \text { Ic, } 15 c \\
15 t(10 \%), 14 t(5 \%)\end{array}$ \\
\hline \multirow[t]{2}{*}{ w46I } & Linoleic & $\begin{array}{c}\text { (i) } \text { I } 8: 2,9 c, \text { I I t } \\
\text { (ii) } 18: \text { : }(\text { trans } 50 \%) \text { IIt }(65 \%) \\
(\text { cis } 50 \%) \text { IIc }(85 \%)\end{array}$ & $\begin{array}{l}\text { Iot }(18 \%), \text { I2t }(12 \%), 9 \text { t }(2 \%) \\
\text { IOc }(10 \%), 9 \text { c }(1 \%)\end{array}$ \\
\hline & Linolenic & 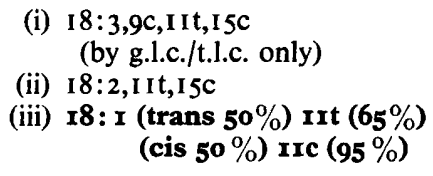 & $\begin{array}{l}\text { Iot }(20 \%), \text {, } 2 \text { t }(15 \%), 9 \text { t }(1 \%) \\
\text { IOc }(5 \%)\end{array}$ \\
\hline \multirow[t]{2}{*}{$\mathrm{F} 2 / 6$} & Linoleic & $\begin{array}{c}\text { (i) } 18: 2,9 \mathrm{c}, \mathrm{I} \text { It } \\
\text { (ii) } \mathrm{I} 8: \mathrm{I} \text { ( (trans } 95 \%) \\
\text { (cis } 5 \%)\end{array}$ & $\begin{array}{l}\text { Iot }(30-70 \%), \text { Irt }(70-30 \%) \\
9 c(47 \%), \operatorname{Ioc}(47 \%), \text { I Ic }(5 \%), 8 \mathrm{c}(2 \%)\end{array}$ \\
\hline & Linolenic & $\begin{array}{c}\text { (i) } 18: 3,9 c, \text { I It, I5c } \\
\text { (ii) } 18: 2, \text { I It, } 15 \mathrm{c} \\
\text { (iii) } 18: \text { I (trans } 95 \%) \\
(\text { cis } 5 \%)\end{array}$ & $\begin{array}{l}\text { Trace IOc, I5c and Iot, I5c } \\
\text { rot }(30-70 \%), \text { Irt }(70-30 \%) \\
\text { Ioc }(45 \%), 9 c(35 \%), \text { I Ic }(20 \%)\end{array}$ \\
\hline \multirow[t]{2}{*}{$\mathbf{F} 2 / 2$} & Linoleic & $\begin{array}{l}\text { (i) } 18: 2,9 c, \text { I It } \\
\text { (ii) } 18: \text { r, xxt }(95 \%)\end{array}$ & $\operatorname{lot}(5 \%)$ \\
\hline & Linolenic & $\begin{array}{l}\text { (i) } 18: 3,9 c, \text { I It, I5c } \\
\text { (ii) } 18: 2, \text { IIt,15c } \\
\text { (iii) } 18: \text { I, I It (usually poor } \\
\text { conversion }-5 \% \text { ) }\end{array}$ & Trace $9 \mathrm{c}, 15 \mathrm{c}$ and others \\
\hline
\end{tabular}

low that identification was only possible by g.l.c. and t.l.c. No isomeric, conjugated, dienoic or trienoic acids were detected during the structural analysis of these products.

At the first hydrogenation stage, isomers became apparent when bond positions and geometry were examined by partial reduction and oxidation. With linoleic acid, by analogy with results obtained with rumen organisms, the trans-octadec-I I-enoic acid was expected to be the major octadecenoic acid with a spectrum of close structural isomers in small amounts.

Table 2 shows that trans-octadec-II-enoic acid was the predominant isomer found with four of the organisms. Strain F2/6 produced a variable mixture of the trans-IO and trans-I I. 
The $5 \%$ of cis component found with F2/6 was richest in the cis-IO acid, the cis-I I isomer being least abundant. Strain W46I gave an equal distribution between cis and trans octadecenoic acids but the cis-I I isomer accounted for $85 \%$ of the cis acids recovered. Good yields (90 to $100 \%$ ) of octadecenoic acids were obtained at $24 \mathrm{~h}$ with w46I, F2/2 and F2/6 from linoleic acid, but $\mathrm{P} 2 / 2$ and T344, which hydrogenated the bulk of the added linoleic acid to stearate, rarely yielded more than $15 \%$ of octadecenoic acid.

With all five organisms the first reduction product from linolenic acid was trans,cisoctadec-II,I5-enoic acid. Small amounts of positional and geometric non-conjugated dienoic acids were found, the most abundant being cis-9, cis-15; cis-10, cis-15; cis-I I, cis-15; and trans-10, cis-15. No trans,trans-isomers were found in sufficient quantities to examine them in detail. Whilst we have not re-incubated these isomers with the organisms, the amounts isolated appear to be related to the amount of non-conjugated octadecadienoic acid recovered, suggesting that they were further metabolized.

The octadecenoic acids recovered from incubations of P2/2 and T344 with linolenic acid were unexpectedly rich in cis-octadec- 15 -enoic acid $(85 \%)$, trans- 15 being the next predominant isomer. With F2/6 and w46I the isomers were very similar, both qualitatively and quantitatively, to those recovered from incubations with linoleic acid. The recoveries of trans-octadec-II-enoic acid with F2/2 were very poor. Other isomers may have been present but these were not recovered in sufficient yield to allow unequivocal characterization.

\section{Re-incubation of products}

Non-conjugated dienoic acid. When re-incubated with the organisms, the non-conjugated dienoic acid formed by the reduction of linolenic acid by the organisms yielded products identical to those obtained at $24 \mathrm{~h}$ with linolenic acid as the substrate.

Hydroxy-stearic acid. Katz \& Keeney (I966 b) suggested that hydroxy acids were the precursors of the keto-acids found in the rumen of hay-fed steers. The hydroxy-stearic acid isolated after growing P2/2 in the presence of oleic acid was re-incubated with P2/2 and with mixed rumen organisms from sheep. No keto-acid was recovered from $\mathbf{P} 2 / 2$ incubations, but there were indications that keto-acid was formed when mixed rumen organisms were used.

In neither experiment was any stearic acid formed; this would have been expected if an hydroxy acid was an intermediate in hydrogenation.

Cis-octadec-I5-enoic acid. On re-incubation, this acid was not converted to either stearic acid or hydroxy-stearic acid by either mixed rumen organisms from sheep or the isolates P2/2 and T344. The substrate was recovered unchanged except for traces of trans-isomer.

\section{Mixed culture hydrogenation}

Linolenic acid was incubated for $24 \mathrm{~h}$ with a growing, mixed culture of P2/2, F2/6 and W46I. The products were identical with those obtained with $\mathrm{P} 2 / 2$ alone (Table 2). From the numbers of each organism seen in stained preparations, growth of all three bacteria appeared to be equally good.

\section{Washed cell suspensions}

Strains P2/2 and F2/6 were grown for $24 \mathrm{~h}$ after inoculating $5 \mathrm{ml}$ of a young culture into I $00 \mathrm{ml}$ of the basic medium without agar. The bacteria were centrifuged using a Sorval bench centrifuge and washed once with buffer (Coleman, 1958) which had been boiled and gassed with oxygen-free $\mathrm{N}_{2}$ while cooling. L-Cysteine $(0.5 \mathrm{mg} / \mathrm{ml})$ was added. The bacteria 
were finally suspended in $5 \mathrm{ml}$ of the same buffer and incubated for $4 \mathrm{~h}$ at $39{ }^{\circ} \mathrm{C}$ with linolenic acid $(2 \mu \mathrm{g} / \mathrm{ml})$ as substrate. Only very low activity was detected.

\section{Hydrogen donors}

An emulsion of linolenic acid $(2 \mu \mathrm{g} / \mathrm{ml})$ was added to a $24 \mathrm{~h}$ culture of the organism under test, together with either sodium formate $(45 \mathrm{~mm})$, sodium pyruvate $(30 \mathrm{~mm})$ or sodium succinate $(20 \mathrm{mM})$, and the mixture incubated for $10,20,60$ and $120 \mathrm{~min}$. In no experiment was even marginal enhancement of hydrogenation activity found.

\section{DISCUSSION}

The numbers in the rumen of each of the five bacteria reported here were between $10^{7}$ and $10^{8}$ viable bacteria $/ \mathrm{ml}$ rumen fluid, indicating that they are true rumen anaerobes and not chance isolations. Their ability to hydrogenate unsaturated fatty acids may be taken as further confirmation.

Isolate $\mathrm{P} 2 / 2$ has been named as a new species, Fusocillus babrahamensis. It is possible that three of the other four are also new species which have not, as far as we are aware, been isolated elsewhere and have certainly not been associated with hydrogenation activity. Ruminococcus albus is an established, but somewhat heterologous, rumen species.

From our investigations it is clear that hydrogenation is not an uncommon activity among rumen bacteria, though in our hands only a few strains of the bacteria isolated were very active. One can still only speculate on the necessity for hydrogenation in the rumen. We have not shown that moderate levels of unsaturated fatty acids are inhibitory to, or necessary for, growth of these bacteria. However, since the isolates were not repeatedly cultured either in unsaturated fatty acid-free media or in a medium containing high levels of these acids, the findings are not conclusive. Henderson (1973) demonstrated the variable effects of adding free fatty acids to pure cultures of six rumen bacteria, and the depression of methane production and rumen metabolism in vivo by large amounts of unsaturated fatty acids is well documented (Czerkawski, Blaxter \& Wainman, 1966; DeMeyer \& Henderickx, 1967). Whether these effects would be more dramatic in the absence of hydrogenation is not clear. It is possible that some anaerobes can use unsaturated fatty acids as a hydrogen sink, thus gaining a slight advantage over organisms not able to hydrogenate. Any rumen organisms to which unsaturated fatty acids are toxic would also benefit.

Qualitatively, the intermediates and products of hydrogenation by the five isolates are the same as were found in vitro and in vivo with mixed sheep-rumen micro-organisms (Dawson \& Kemp, 1970). Cis-octadec-I 5-enoic acid, produced in high yields by isolates P2/2 and T344, has never been observed in large amounts in the rumen. It has been detected from time to time by t.l.c. and g.l.c., since it has a unique retention time on PEGA at $184^{\circ} \mathrm{C}$ (methyl ester $2 \cdot 23$ relative to methyl palmitate).

Trans-octadec-Io-enoic acid, produced in large amounts by isolate F2/6, has been found only in small quantities in the rumen (Katz \& Keeney, 1966a). However, on one occasion this acid was found as the major octadecenoic acid in the depot fat of an apparently normal five-month-old lamb (W. M. F. Leat and P. Kemp, unpublished observation). Large amounts of cis octadecenoic acids other than oleic acid have not been found in the rumen. Thus the finding of equal amounts of cis and trans octadecenoic acids in incubations of isolate w46r with linoleic and linolenic acid was unexpected. However, since neither the relative numbers of each hydrogenating organism nor their abilities to hydrogenate in vivo are known, we cannot estimate the products from a mixed rumen population. Further, one 
would expect fluctuations in numbers, and a large change in numbers of one or more hydrogenators due to a dietary or physiological stimulus could account for the unusual result from one lamb described above. None of our results are incompatible with the findings with mixed populations from the rumen.

The number of positional and geometric isomers found in the monoenoic and dienoic acids is greater with mixed populations than with a pure culture. However, we have no reason to believe that the precursor of the monoenoic acids derived from linolenic is other than trans,cis-octadec-I I, I 5-enoic acid. Some of the dienoic acid isomers derive from this acid, but the monoenoic acids, especially the trans ones, seem readily interconverted. The ability to isomerize these acids would be an advantage, since many isomers occur in plants and the bacteria might therefore be able to hydrogenate a wider spectrum of substrates. We have examined only four monoenoic acids, but only the cis-I5 isomer appears not to be further metabolized.

Much work remains to be done to show how the monoenoic acids are hydrogenated to stearic. It has been suggested (Dawson \& Kemp, 1970) that oleic acid, which is hydrogenated faster than the other monoenoic acids tested, may be more easily converted to a preferred isomer than either trans -9 or trans-II - if, indeed, it is not itself the preferred isomer. Experiments to identify the penultimate product are in progress.

In this connexion the results reported here do not implicate an hydroxy acid as an intermediate, nor suggest why three of the organisms were unable to produce stearic from linolenic or linoleic acids although producing high yields of its normal precursors, trans monoenoic acids. It is possible that our growth medium was deficient. In a mixed rumen population trans monoenoic acids produced by one group of organisms could be converted to stearic acid by another group. This suggestion has some substance, since the more unsaturated acids are more rapidly hydrogenated by rumen bacteria to monoenoic acids than are the monoenoic acids to stearic acid (Dawson \& Kemp, 1970). Our experiments show that isolate $\mathrm{P} 2 / 2$ has a higher affinity for linolenic acid than $\mathrm{F} 2 / 6$ and $\mathrm{W} 46 \mathrm{I}$ when grown in mixed culture, since the product with linolenic acid as substrate was mainly the cis-I5 monoenoic acid with no stearic acid or trans-I I monoenoic acid.

It was disappointing to find that the five bacteria were no more resistant to washing than was Butyrivibrio fibrisolvens (Kepler \& Tove, 1967), and that none of the metabolic intermediates which we tested were active as hydrogen donors.

Saturated fatty acids, derived by hydrogenation from dietary unsaturated fatty acids in the rumen and laid down in ruminant depot fat and secreted in milk, have been implicated as a factor in human coronary diseases (Jones, 1974). Accordingly, methods have been developed to decrease the level of saturated acids and increase the unsaturated fatty acids in ruminant products. Protected seed oils have been fed. These were not hydrolysed in the rumen, and hence the fatty acids were not hydrogenated but were absorbed in the intestine and incorporated into carcase and milk fat (Scott \& Cook, 1973).

If lipolysis could be prevented or reduced when the animals were fed a normal diet, hydrogenation would also be reduced. Alternatively, hydrogenation might be controllable if we had a precise knowledge of the metabolic processes leading to the reduction of free fatty acids by rumen bacteria. At present we are trying to identify the hydrogen donors in hydrogenation, with a view to effecting control at this stage. The effects of such control measures on the rumen bacterial and protozoal populations will also be carefully examined to see the overall effects on rumen metabolism. 
We are grateful to Dr R. M. C. Dawson for his interest and encouragement, to Dr E. A. Munn for preparing electron micrographs, to Mrs M. Black for skilled technical assistance, and to Mr P. Barker for enzymic estimations of lactic acid.

\section{REFERENCES}

BARKer, J. N. \& Britton, H. G. (1957). The enzymatic estimation of L(+)-lactic acid. Journal of Physiology $\mathbf{I 3 8}, 3 P$.

Barnes, E. M. \& BurTon, G. C. (1970). The effect of hibernation on the caecal flora of the thirteen-lined ground squirrel (Citellus tridecemlineatus). Journal of Applied Bacteriology 33, 505-514.

BRYANT, M. P. (1959). Bacterial species of the rumen. Bacteriological Reviews 23, 125-153.

BRYANT, M. P. \& RoBINSON, I. M. (1961). An improved nonselective culture medium for ruminal bacteria and its use in determining diurnal variation in numbers of bacteria in the rumen. Journal of Dairy Science 44, 1446-1456.

BRYANT, M. P. \& SMALl, N. (1956). The anaerobic monotrichous butyric acid-producing curved rod-shaped bacteria of the rumen. Journal of Bacteriology 72, 16-21.

Chanda, S. K., Hirst, E. L., Jones, J. K. N. \& Percival, E. G. V. (1950). The constitution of xylan from esparto grass (Stipa tenacissima L.). Journal of the Chemical Society, 1289-1297.

ClelaND, W. W. (1964). Dithiothreitol, a new protective reagent for SH groups. Biochemistry 3, 480-482.

Coleman, G. S. (1958). Maintenance of oligotrich protozoa from the sheep rumen in vitro. Nature, London 182, I 104-I 105 .

Cowan, S. T. \& SteEL, K. J. (1966). Manual for the Identification of Medical Bacteria. Cambridge: Cambridge University Press.

Czerkawski, J. W., Blaxter, K. L. \& Wainman, F. W. (1966). The metabolism of oleic, linoleic and linolenic acids by sheep with reference to their effects on methane production. British Journal of Nutrition 20, 349-362.

Dawson, R. M. C., Hemington, N., Grime, D., LANDer, D. \& Kemp, P. (1974). Lipolysis and hydrogenation of galactolipids and the accumulation of phytanic acid in the rumen. Biochemical Journal 144, 169-171.

DAwson, R. M. C. \& KeMP, P. (1970). Biohydrogenation of dietary fats in ruminants. In Physiology of Digestion and Metabolism in the Ruminant, pp. 504-518. Edited by A. T. Phillipson. Newcastle: Oriel Press.

DeMeYer, D. I. \& Henderickx, H. K. (1967). The effect of $C_{18}$ unsaturated fatty acids on methane production in vitro by mixed rumen bacteria. Biochimica et biophysica acta 137, 484-497.

GaRTon, G. A., Lough, A. K. \& VIOQUE, E. (196I). Glyceride hydrolysis and glycerol fermentation by sheep rumen contents. Journal of General Microbiology 25, 215-225.

Gutierrez, R. E., Davis, I. L., LiNDAHL, I. L. \& WARWICK, E. J. (1959). Bacterial changes in the rumen during the onset of feed-lot bloat of cattle and characteristics of Peptostreptococcus elsdenii n.sp. Applied Microbiology 7, 16-22.

HAWKE, J. C. \& SILCOCK, W. R. (1969). Lipolysis and hydrogenation in the rumen. Biochemical Journal r12, I3I-I32.

HENDERSON, C. (1973). Effects of fatty acids on pure cultures of rumen bacteria. Journal of Agricultural Science 81, 107-112.

Holdeman, L. V. \& Moore, W. E. C. (1973). An Anaerobic Laboratory Manual, 2nd edn. Blacksbury, Virginia: Virginia Polytechnic Institute.

Hungate, R. W. (1966). The Rumen and its Microbes. New York and London: Academic Press.

Jones, R. J. (1974). Role of dietary fat in health. Journal of the American Oil Chemists Society 5r, 25I-254.

KATZ, I. \& KeENEY, M. (1966a). Characterization of octadecenoic acids in rumen digesta and rumen bacteria. Journal of Dairy Science 49, 962-966.

KATZ, I. \& KeENEY, M. (I966b). Occurrence of ketostearic acids in the rumen. Journal of Dairy Science 49, $967-970$.

KemP, P. \& Dawson, R. M. C. (1968). Isomerisation of linolenic acid by rumen microorganisms. Biochemical Journal rog, 477-478.

KEMP, P. \& WHITE, R. W. (1968). The biohydrogenation of linolenic and linoleic acids by bacteria isolated from an ovine rumen. Biochemical Journal 106, 55 P.

Kepler, C. R., Hirons, K. P., McNiell, J. J. \& Tove, S. B. (1966). Intermediates and products of the biohydrogenation of linoleic acid by Butyrivibrio fibrisolvens. Journal of Biological Chemistry 24r, 1350-1354. 
KEPLER, C. R. \& Tove, S. B. (1967). Biohydrogenation of unsaturated fatty acids. III. Purification and properties of a linoleate $\Delta^{12}$-cis, $\Delta^{11}$-trans-isomerase from Butyrivibrio fibrisolvens. Journal of Biological Chemistry 242, 5686-5692.

KePleR, C. R., TUCKER, W. P. \& TOVE, S. B. (1970). Biohydrogenation of unsaturated fatty acids. IV. Substrate specificity and inhibition of linoleate $\Delta^{12}$-cis, $\Delta^{11}$-trans-isomerase from Butyrivibrio fibrisolvens. Journal of Biological Chemistry 245, 361 2-3620.

LANCEFIELD, R. C. (I933). A serological differentiation of human and other groups of hemolytic streptococci. Journal of Experimental Medicine 57, 571-595.

LEv, M. (1958). Apparent requirement for vitamin $\mathrm{K}$ of rumen strains of Fusiformis nigrescens. Nature, London 181, 203-204.

Mills, S. C., Scott, T. W., Russell, G. R. \& Smith, R. M. (1970). Hydrogenation of $C_{18}$ unsaturated fatty acids by pure cultures of a rumen micrococcus. Australian Journal of Biological Sciences 23, IIO9-III3.

MoORE, W. B. (1968). Solidified media suitable for the cultivation of Clostridium novyi type B. Journal of General Microbiology 53, 415-423.

Noble, R. C., SteELE, W. \& Moore, J. H. (1969). The incorporation of linoleic acid into the plasma lipids of sheep given intraruminal infusion of maize oil or free linoleic acid. British Journal of Nutrition 23, 709-7I4.

Orpin, C. G. \& MUNN, E. A. (1974). The occurrence of bacteriophages in the rumen and their influence on rumen bacterial populations. Experientia 30, 1018-1020.

Polan, C. E., McNeill, J. J. \& Tove, S. B. (I964). Biohydrogenation of unsaturated fatty acids by rumen bacteria. Journal of Bacteriology 88, 1056-1064.

PrivetT, O. S. \& Nickell, E. C. (1966). Determination of the specific positions of $c$ is and trans double bonds in polyenes. Lipids $\mathrm{I}, 98-\mathrm{I0}$.

Provost, P. J. \& Doetsch, R. N. (1960). An obligate anaerobic amylolytic coccus from the bovine rumen. Journal of General Microbiology 22, 259-264.

RoEHM, J. N. \& PRIVETT, O. S. (I969). Improved method for determination of the position of double bonds in polyenoic fatty acid esters. Journal of Lipid Research 1o, 245-246.

RosenFELD, I. S. \& TovE, S. B. (1971). Biohydrogenation of unsaturated fatty acids. VI. Source of hydrogen and stereospecificity of reduction. Journal of Biological Chemistry 246, 5025-5030.

VON RUDlOFF, E. (1956). Periodate-permanganate oxidations. V. Oxidation of lipids in media containing organic solvents. Canadian Journal of Chemistry 34, 1413-1418.

Russell, G. R. \& SMITH, R. M. (1968). Reduction of heliotrine by a rumen micro-organism. Australian Journal of Biological Sciences 21, I277-1290.

SACHAN, D. S. \& DAVIS, C. L. (1969). Hydrogenation of linoleic acid by a rumen spirochete. Journal of Bacteriology 98, 300-301.

SchlenK, H. \& Gellerman, J. L. (I960). Esterification of fatty acids with diazomethane on a small scale. Analytical Chemistry 32, 1412-1414.

ScotT, T. W. \& Cook, L. J. (1973). Dietary modifications of ruminant milk and meat fats. In The Coronary Heart Disease and Dietary Fat Controversy, pp. 48-64. Wellington: Editorial Services.

Sebald, M. (1962). Étude sur les bacteries anaerobies Gram-negative asporulées. Laval: Barneoud.

SWern, D. \& SCANlan, J. T. (I953). Elaidic acid. Biochemical Preparations 3, 118-1 20.

VIVIANI, R. (1970). Metabolism of long-chain fatty acids in the rumen. In Advances in Lipid Research, vol. 8, pp. 267-345. Edited by R. Paoletti. New York: Academic Press.

WALKER, D. J. (196I). Isolation and characterisation of a hemicellulose fermenting bacterium from the rumen. Australian Journal of Agricultural Research 12, 171-I75.

WHITE, R. W. (1970). A closed culture vessel for colony counts of anaerobic bacteria, with a note on isolation from a mixed population. Laboratory Practice 19, 180.

WhITE, R. W. \& KEMP, P. (1971). Sheep rumen bacterial isolates which biohydrogenate unsaturated dietary fatty acids. Journal of General Microbiology 68, vi-viii.

White, R. W., KeMP, P. \& DAwson, R. M. C. (1970). Isolation of a rumen bacterium that hydrogenates oleic acid as well as linoleic acid and linolenic acid. Biochemical Journal Ir6, 767-768.

White, R. W., MACKenziE, H. R. \& Bousfield, I. J. (1974). Successful freeze-drying and retention of biohydrogenation activity of bacteria isolated from the ovine rumen. Journal of Applied Bacteriology 37, vi.

WILDE, P. F. \& DAWSON, R. M. C. (1966). The biohydrogenation of $\alpha$-linolenic acid and oleic acid by rumen micro-organisms. Biochemical Journal 98, 469-475. 